\title{
MAKING CITIES INTEROPERABLE IN TURKEY
}

\author{
H. Bayraktar ${ }^{1}$, D. Y. Bayar ${ }^{1}$, G. Bilgin ${ }^{1, *}$ \\ ${ }^{1}$ Ministry of Environment and Urbanization, Directorate General of Geographic Information Systems, 06530 Çankaya Ankara, \\ Turkey - (huseyin.bayraktar, dyildirim.bayar, gokhan.bilgin)@csb.gov.tr
}

KEY WORDS: Smart Cities, Interoperability Model, Interoperability in Smart Cities, Technical Interoperability, Semantic Interoperability, Organizational Interoperability, Smart City Interoperability Model of Turkey

\begin{abstract}
:
The population of cities is increasing rapidly day by day, and it is predicted that this increase will continue in the following years. Accordingly, population growth creates a significant pressure in many different domains of cities such as infrastructure, traffic, energy, and environment. Smart cities come forward as a useful option to struggle with the pressure on cities caused by overwhelming population growth and to make cities liveable and sustainable. Smart city approach creates gains in the fields of sustainable development, competitiveness and environmental sustainability with its ability to transform information into economic, social and environmental benefits. However, smart city services and applications are mostly designed as independent and unrelated units so this approach causes isolated and heterogeneous data and technology islands. As the result, data flow problem occurs between vertical applications and service suppliers, and this interoperability problem causes emergence of independent silos in smart cities. Such silos hinders data integration, prevent citizens and public administrations benefit fully from smart cities, and cause vendor lock-in. In order to use the full potential of smart city approach, it's vital to secure interoperability systems and applications of smart cities. In this study, interoperability terms and their necessity for smart city ecosystem will be addressed. Afterwards, Smart City Interoperability Model's (SCIM) contributions to semantic, technical and operational interoperability will be discussed.
\end{abstract}

\section{INTRODUCTION}

Population of cities is increasing unprecedentedly day by day. In $1950, \% 30$ of the world's total population was residing in cities and this number increased up to \%54 in 2014 (United Nations Department of Economic and Social Affairs, 2014). Global population is expected to rise to 8.6 billion in 2030, 10.1 billion in 2050 and 12.7 billion in 2100 (United Nations Department of Economic and Social Affairs, 2019).

Smart cities come forward as a useful option to struggle with the pressure on cities caused by overwhelming population growth and make cities liveable and sustainable. Smart city approach creates gains in the fields of sustainable development, competitiveness and environmental sustainability with its ability to transform information into economic, social and environmental benefits.

In this context, ICT is the key-enabler for implementing innovative solutions, services and applications to make cities "smart" (Petrolo et al., 2015). Especially IoT (Internet of Things) technologies are being leveraged in many domains all around the world, including smart cities (A. Gyrard and M. Serrano, 2016).

However, smart city services and applications are mostly designed as independent and unrelated units (J. Hwang et al., 2019) so this approach causes isolated and heterogeneous data and technology islands. As the result, data flow problem occurs between vertical applications and service suppliers, and this interoperability problem causes emergence of independent silos in smart cities (Brutti et al., 2019). Such silos use different communication technologies, architectures and standards as well (A. Kazmi et al., 2018) and hinder data integration, prevent citizens and public administrations benefit fully from smart cities and causing vendor lock-in (A. Brutti et al., 2018).

\begin{abstract}
"Interoperability" establishes a relationship between heterogeneous systems to ensure exchanging data and coordinating processes (B. Molina et al., 2014). Integrating such heterogeneous devices and system also contribute to enabling IoT technologies in smart cities (A. Gharaibeh et al., 2017).
\end{abstract}

2020-2023 Smart Cities Strategy and Action Plan of Turkey (SAP) was published in December 2019 to ensure interoperability by bringing a holistic perspective to smart city policies at the national level, to prioritize investments in line with the determined policies, and to ensure that the investments are implemented with the right projects and activities (Bayar et al., 2020).

Within the context of SAP, 26 actions are defined in total, and sixteenth action is determined as "Smart City Terminology, Smart City Data Dictionary, Interoperability Model and Reference Architectural Model will be created.", and one of the subgoals of the action is "SCIM will be prepared" (The Ministry of Environment and Urbanization of Turkey, 2019).

This paper will, in Section 2, discuss the interoperability term and the levels of interoperability. After that, in Section 3, interoperability within the scope of SAP was discussed and recommendations for smart city stakeholders that are expected to contribute to technical, semantic and operational interoperability were mentioned. Finally, Section 4 concludes the paper.

\section{INTEROPERABILITY IN SMART CITIES}

The concept of interoperability was used for the first time in the military field. In the study of the US Department of Defence in

Corresponding author 
1977, it was defined as "The ability of systems, units or forces to provide services to and accept services from other systems, units, or forces and to use the services so exchanged to enable them to operate effectively together." (DOD, 1977) (Kubicek et al., 2011). One of the definitions of the term interoperability, which is especially important for information systems, is defined as "the ability of two or more systems or components to exchange information and to use the information that has been exchanged" in the Institute of Electrical and Electronics Engineers (IEEE) dictionary named "IEEE Standard Computer Dictionary" (IEEE, 1990). Another definition of this term is defined in the European Interoperability Framework as "the ability of organisations to interact towards mutually beneficial goals, involving the sharing of information and knowledge between these organisations, through the business processes they support, by means of the exchange of data between their ICT systems.” (European Commission, 2017).

In line with these definitions, issues to ensure interoperability can be addressed at three different levels: technical, semantic and organizational (Novakouski and Lewis, 2012).

Technical interoperability: The data used and produced within the concept of smart cities is usually locked-in one system, domain or service provider and it is challenging to make the data shared and re-used by other applications, providers and systems (Karpenko et al., 2018).

In general terms, technical interoperability ensures data exchange. Therefore, it copes with protocol, connectivity, time management and other hardware and software related issues (Diallo et al., 2011). As data is one of the core components of smart cities (Wang et al., 2014), technical interoperability could be considered as the base of the whole interoperability ecosystem. Breaking silos between various applications is only possible by ensuring technical interoperability.

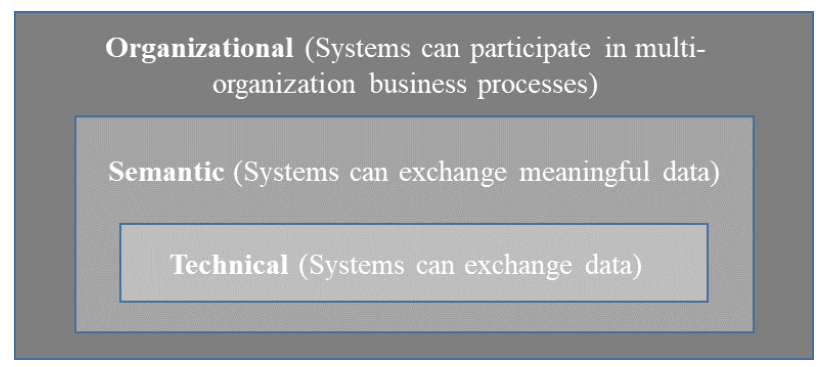

Figure 1. Interoperability Levels (Novakouski and Lewis, 2012)

Semantic Interoperability: While technical interoperability deals with technical issues during the exchange of data, semantic interoperability focuses on the "meaning" of data. Usually, stakeholders of cities tend to collect data for their applications or projects and mostly the data is not structured in a standard way to share with other smart city stakeholders that can reuse the data in similar smart city applications (Chaturvedi and Kolbe, 2019).

The aim of semantic interoperability is to use explicit semantic descriptions, thus, it will be possible to facilitate information and systems integration (Kalfoglou et al., 2005). With semantic interoperability it is possible to create a common understanding between the requested service and data (Heiler, 1995). Also, leveraging relative ontologies can support semantic interoperability (Gyrard et al., 2018).
Organizational Interoperability: Organizational Interoperability is the ability of organizations to communicate and transfer data effectively, even if they are using different information systems based on separate infrastructure (ETSI, 2008). (Hellman, 2010) addressed the barriers to organizational interoperability as low competency, lack of measurable, economic restrictions, absence of national joint efforts, project archipelago, disharmony in legislation, anaemic arenas, invisible best practice, the human factor, ubiquitous heterogeneity.

In order to establish organizational interoperability, it is necessary to address all administrative units in the ecosystem, and determine their roles and the functions under their responsibility (Yazici and Özdemirci, 2019).

\section{SMART CITY INTEROPERABILITY MODEL OF TURKEY}

Lately, cities carry out separate heterogeneous solutions related to different smart city domains. In order to use the full potential of the smart city approach, it's vital to secure interoperability between these solutions (Brutti et al., 2019).

Solving interoperability issues in a particular focus area can be relatively easy by using a set of common standards. However, each of the smart city domains has developed independently from other areas for years and has created its own terminology. Therefore, there are many applications already running in every field and numerous datasets have been defined. Although it is theoretically possible to create a semantic model to cover all these areas and wait for the stakeholders in all these areas to leave the existing data structures, switch to this model will bring a huge cost in practice.

Instead of such a transition, it would be more realistic to match existing datasets with a determined model so that it can be understood by all stakeholders. For this reason, with SCIM, existing frameworks and standards have been proposed that will contribute to the work of all smart city stakeholders in terms of semantic, technical and organizational aspects, rather than introducing new standards and models.

\subsection{Semantic Interoperability}

As a result of systematic research on the subject of interoperability in smart cities, two semantic models that can be directly called "Smart Cities Interoperability Models" have been identified. The first one of these models is PAS 182 \& ISO/IEC 30182 - Smart City Conceptual Model (BSI, 2014).

On the one hand, PAS 182, which defines an effective framework for establishing interoperability, outlines various concepts and the interrelationships between them. This comprehensive framework, defined by concepts and relationships, is general enough that it can be used to describe data from any industry regarding smart cities.

On the other hand, the smart city conceptual model provided by PAS 182 does not claim to remove all obstacles to interoperability. Decision makers should consider issues such as ensuring compliance, confidentiality, security, integrity, availability and data quality.

\begin{tabular}{lll}
\hline Component & $\begin{array}{l}\text { Technology } \\
\text { /Standard }\end{array}$ & Explanation \\
\hline
\end{tabular}




\begin{tabular}{|c|c|c|}
\hline $\begin{array}{l}\text { Smart City } \\
\text { Conceptual } \\
\text { Model }\end{array}$ & PAS 182 & $\begin{array}{l}\text { The smart city concept } \\
\text { model (SCCM), outlined } \\
\text { in PAS } 182 \text { by the } \\
\text { British Standards } \\
\text { Institute (BSI), addresses } \\
\text { the lack of } \\
\text { interoperability by } \\
\text { defining an overarching } \\
\text { framework of concepts } \\
\text { and relationships that can } \\
\text { be used to describe data } \\
\text { from any industry. }\end{array}$ \\
\hline $\begin{array}{l}\text { Smart City } \\
\text { Onthology }\end{array}$ & SAREF4CITY & $\begin{array}{l}\text { SAREF4CITY document } \\
\text { is a technical } \\
\text { specification document } \\
\text { prepared as an extension } \\
\text { of SAREF for the Smart } \\
\text { Cities domain. }\end{array}$ \\
\hline $\begin{array}{l}\text { Context } \\
\text { Information } \\
\text { Management }\end{array}$ & FIWARE & $\begin{array}{l}\text { FIWARE-NGSI v2 is an } \\
\text { application programming } \\
\text { interface that aims to } \\
\text { manage the entire } \\
\text { lifecycle of context } \\
\text { information, including } \\
\text { updates, queries, } \\
\text { registrations and } \\
\text { subscriptions. }\end{array}$ \\
\hline $\begin{array}{l}\text { Data } \\
\text { interoperability } \\
\text { framework }\end{array}$ & $\begin{array}{l}\text { ITU-T } \\
\text { Technical } \\
\text { Specification } \\
\text { D3.3 }\end{array}$ & $\begin{array}{l}\text { Created by the ITU-T } \\
\text { FG-DPM (Data } \\
\text { Processing and } \\
\text { Management Focus } \\
\text { Group to support IoT and } \\
\text { Smart Cities \& } \\
\text { Communities) focus } \\
\text { group, this technical } \\
\text { specification document } \\
\text { outlines a framework for } \\
\text { supporting data } \\
\text { interoperability in IoT } \\
\text { environments. Relevant } \\
\text { requirements and } \\
\text { technologies that support } \\
\text { data interoperability are } \\
\text { defined in this technical } \\
\text { specification. }\end{array}$ \\
\hline
\end{tabular}

Table 1. Recommended Technologies and Standards for Semantic Interoperability in Smart Cities

This model is a theoretical study that has been created in general that can address almost all vertical areas of the smart city. This model will gain meaning with a mapping work that stakeholders will create to adapt to this model in order to ensure unity of meaning, instead of changing the existing models. In the case of using this model in Turkey, smart city stakeholders should do a matching study for their own datasets. Since the perspective of the model is significantly inclusive, it is thought that a match can be obtained for almost any dataset. With the model, it is possible to collect data from different organizations, facilitate reuse of the data and break the silos within smart cities.

Another semantic study is the SAREF4CITY model. The requirements of this model are built on three usage scenarios: eHealth and Smart Park, Air Quality Monitoring and Mobility, Street Lighting. For this reason, it is clear that SAREF4CITY is not a general model like PAS 182. However, since it is based on the main applications of smart cities, its practical value is quite high. In addition, it is possible to use directly rather than a mapping mechanism like PAS 182 as it contains class structures that software can directly reference. Essentially, even if these two models overlap to a certain extent, they are far from being alternatives to each other. Both are possible and necessary on a case-by-case basis.

Practical field experience shows that interoperability has many other dimensions besides conceptual models. Rather than focusing on a single model that will transcend all these dimensions, it would be more beneficial and realistic to focus on maintaining certain minimum interoperability mechanisms. It is understood and recommended that the frequently used FIWARE Context Information Management API will be an important interoperability mechanism.

Another conclusion reached from the field examples examined is that it is necessary to ensure that many heterogeneous objects work together in order to make interoperability possible in practice. One of the main alternatives to FIWARE, especially in the world of the Internet of Things, is the interfaces provided by OneM2M. These two different structures were successfully combined in a project for the cities of Busan in South Korea and Santander in Spain (J. Hwang et al., 2019).

Since smart city objects are usually chosen for different needs, searching for FIWARE compliance requirement or OneM2M compliance requirement may cause problems in procurement. If possible, it is recommended to create an architecture that will support these two different structures together.

The recommended standards and frameworks that can contribute to semantic interoperability are listed in Table 2 .

\subsection{Technical Interoperability}

As mentioned before, technical interoperability generally copes with data exchange between independent systems and infrastructures. Smart cities should be capable of collecting, analysing and distributing data, and smart city data should remain re-usable (Brutti et al., 2019). Open standards and protocols can be utilized as a key enabler to deal with technical interoperability. If possible technical interoperability should be ensured through the use of formal technical specifications.

Another interoperability barrier demonstrated by field experience is vendor dependency. It is observed that some solutions provided by well-established companies, especially in information and communication technologies, lead to monopolization and vendor dependency over time. For this reason, it is recommended to emphasize the open technical specifications and compliance with international standards.

In this context, standards that can be used for smart city components are proposed in the SCIM. Dissemination of these standards to all components and technology infrastructure will contribute to the interoperability of smart cities. The recommended standards are listed in Table 2 for smart environment, smart transportation and smart energy components, respectively.

\begin{tabular}{lll}
\hline Component & $\begin{array}{l}\text { Technology } \\
\text { /Standard }\end{array}$ Explanation
\end{tabular}


This study contributes to the literature on how to deal with interoperability problems for smart cities on a national scale. As future work, interoperability issues will be addressed in the context of Reference Architectural Model of Interoperability of Turkey (RUMI).

\section{REFERENCES}

A. Brutti, A. Frascella, N. Gessa, P. De Sabbata, C. Novelli, 2018. Interoperability in the Smart City: A Semantic Approach for Merging Flexibility with Strictness, in: 2018 IEEE International Conference on Smart Computing (SMARTCOMP). Presented at the 2018 IEEE International Conference on Smart Computing (SMARTCOMP), pp. 434439. https://doi.org/10.1109/SMARTCOMP.2018.00042

A. Gharaibeh, M. A. Salahuddin, S. J. Hussini, A. Khreishah, I. Khalil, M. Guizani, A. Al-Fuqaha, 2017. Smart Cities: A Survey on Data Management, Security, and Enabling Technologies. IEEE Commun. Surv. Tutor. 19, 2456-2501. https://doi.org/10.1109/COMST.2017.2736886

A. Gyrard, M. Serrano, 2016. Connected Smart Cities: Interoperability with SEG 3.0 for the Internet of Things, in: 2016 30th International Conference on Advanced Information Networking and Applications Workshops (WAINA). Presented at the 2016 30th International Conference on Advanced Information Networking and Applications Workshops (WAINA), pp. 796-802. https://doi.org/10.1109/WAINA.2016.151

A. Kazmi, M. Serrano, A. Lenis, 2018. Smart Governance of Heterogeneous Internet of Things for Smart Cities, in: 2018 12th International Conference on Sensing Technology (ICST). Presented at the 2018 12th International Conference on Sensing Technology (ICST), pp. 58-64. https://doi.org/10.1109/ICSensT.2018.8603657

B. Molina, C. E. Palau, G. Fortino, A. Guerrieri, C. Savaglio, 2014. Empowering smart cities through interoperable Sensor Network Enablers, in: 2014 IEEE International Conference on Systems, Man, and Cybernetics (SMC). Presented at the 2014 IEEE International Conference on Systems, Man, and Cybernetics (SMC), pp. 7-12. https://doi.org/10.1109/SMC.2014.6973876

Bayar, D.Y., Guven, H., Badem, H., Soylu Sengor, E., 2020. NATIONAL SMART CITIES STRATEGY AND ACTION PLAN: THE TURKEY'S SMART CITIES APPROACH. Int. Arch. Photogramm. Remote Sens. Spat. Inf. Sci. XLIV-4/W32020, 129-135. https://doi.org/10.5194/isprs-archives-XLIV-4W3-2020-129-2020

Bayraktar, H., Bayar, D.Y., Kara, B., Bilgin, G., 2020. LEVERAGING MATURITY ASSESSMENT TO CHOOSE THE RIGHT APPLICATIONS FOR SMART CITIES: TURKEY'S APPROACH. Int. Arch. Photogramm. Remote Sens. Spat. Inf. Sci. XLIV-4/W3-2020, 137-142. https://doi.org/10.5194/isprs-archives-XLIV-4-W3-2020-1372020

Brutti, A., De Sabbata, P., Frascella, A., Gessa, N., Ianniello, R., Novelli, C., Pizzuti, S., Ponti, G., 2019. Smart City Platform Specification: A Modular Approach to Achieve Interoperability in Smart Cities, in: Cicirelli, F., Guerrieri, A., Mastroianni, C., Spezzano, G., Vinci, A. (Eds.), The Internet of Things for Smart
Urban Ecosystems. Springer International Publishing, Cham, pp. 25-50. https://doi.org/10.1007/978-3-319-96550-5_2

BSI, 2014. PAS 182 - Smart city concept model.

Chaturvedi, K., Kolbe, T.H., 2019. Towards Establishing CrossPlatform Interoperability for Sensors in Smart Cities. Sensors 19. https://doi.org/10.3390/s19030562

Diallo, S., Herencia, H., Padilla, J., Tolk, A., 2011. Understanding interoperability.

DOD, 1977. Standardization and Interoperability of Weapon Systems and Equipment within the North Atlantic Treaty Organization (NATO).

ETSI, 2008. Achieving Technical Interoperability - the ETSI Approach.

European Commission, 2017. New European Interoperability Framework.

Gyrard, A., Zimmermann, A., Sheth, A., 2018. Building IoTBased Applications for Smart Cities: How Can Ontology Catalogs Help? IEEE Internet Things J. PP, 1-1. https://doi.org/10.1109/JIOT.2018.2854278

Heiler, S., 1995. Semantic Interoperability. ACM Comput Surv 27, 271-273. https://doi.org/10.1145/210376.210392

Hellman, R., 2010. Organisational barriers to interoperability.

IEEE, 1990. Standard Computer Dictionary.

J. Hwang, J. An, A. Aziz, J. Kim, S. Jeong, J. Song, 2019. Interworking Models of Smart City with Heterogeneous Internet of Things Standards. IEEE Commun. Mag. 57, 74-79. https://doi.org/10.1109/MCOM.2019.1800677

Kalfoglou, Y., Schorlemmer, M., Uschold, M., Sheth, A., Staab, S., 2005. Semantic Interoperability and Integration.

Karpenko, A., Kinnunen, T., Madhikermi, M., Robert, J., Främling, K., Dave, B., Nurminen, A., 2018. Data Exchange Interoperability in IoT Ecosystem for Smart Parking and EV Charging. Sensors 18. https://doi.org/10.3390/s18124404

Kubicek, H., Cimander, R., Scholl, H., 2011. Organizational Interoperability in E-Government. https://doi.org/10.1007/9783-642-22502-4

Novakouski, M., Lewis, G., 2012. Interoperability in the eGovernment Context.

Petrolo, R., Loscri, V., Mitton, N., 2015. Towards a smart city based on cloud of things, a survey on the smart city vision and paradigms. Trans. Emerg. Telecommun. Technol. 28. https://doi.org/10.1002/ett.2931

The Ministry of Environment and Urbanization of Turkey, 2019. 2020-2023 National Smart Cities Strategy and Action Plan.

United Nations Department of Economic and Social Affairs, 2019. World Population Prospects 2019.

United Nations Department of Economic and Social Affairs, 2014. World urbanization prospects: the 2014 revision. 
Wang, J., Li, C., Xiong, Z., Shan, Z., 2014. Survey of datacentric Smart City. Jisuanji Yanjiu Yu FazhanComputer Res. Dev. 51, 239-259. https://doi.org/10.7544/issn10001239.2014.20131586

Yazici, S., Özdemirci, F., 2019. Bilgi Yönetim Sistemlerinin Birlikte Çalışabilirlik Gereksinimleri ve Elektronik Belge Yönetim Sistemi Birlikte Çalışabilirlik Olgunluk Modeli. Bilgi Önetimi 84-105. https://doi.org/10.33721/by.624077 